\title{
Pengembangan Bandar Udara Harun Thohir Bawean dengan Konsep Termoakustik
}

\author{
Chandra Miraz Angkoso Putro dan F.X. Teddy Badai Samodra \\ Departemen Arsitektur, Fakultas Arsitektur, Desain dan, Perencanaan, Institut Teknologi Sepuluh \\ Nopember (ITS) \\ e-mail:fxteddybs@arch.its.ac.id
}

\begin{abstract}
Abstrak-Semenjak adanya Bandar Udara Harun Thohir, Bawean menjadi lebih mudah untuk dijangkau. Akibatnya, moda transportasi udara akan berkembang. Sehingga perlu adanya pengembangan Bandar Udara Perintis Harun Thohir, Bawean. Dalam pengembangan desain objek bandar udara ini, fokus terhadap kenyamanan termal dan kenyamanan akustik pengguna. Hal tersebut difokuskan dalam integrasi antara termal dan akustik (termoakusik). Selain itu, dalam desain objek kali ini perlu memperlihatan arsitektur asli bawean sehingga perlu adanya bentuk arsitektur bawean dalam bentuk yang mengkini dengan menggunakan strategi paradigma re-interpreting tradition. Hasil dari desain ini merupakan bandar udara yang nyaman akan aspek termal dan akustik sehingga tercipta integrasi antara kedua aspek tersebut. Selain itu, hasil dari desain bandar udara ini dapat memperlihatkan lokalitasnya dari bentuk, ruang dalam, dan zonifikasi
\end{abstract}

Kata Kunci-Bawean, Bandar Udara, Re-Interpreting Tradition, Lumbung Dhurung, Termal, Akustik.

\section{PENDAHULUAN}

$\mathrm{P}$ ERJALAN menuju Bawean, guna kegiatan sehari-hari maupun kegiatan wisata, menggunakan moda transportasi laut. Sayangnya hal tersebut belum mampu memeunuhi fungsi tersebut. Tetapi, sejak diresmikannya bandar udara Pulau Bawean menjadi lebih mudah untuk dijangkau. Hal tersebut memungkinkan moda transportasi udara akan berkembang, mulai dari penambahan jadwal penerbangan, penambahan rute penerbangan, hingga tempat transit menuju beberapa tempat. Akibatnya pengguna akan semakin banyak. Karena hal tersebut, butuh adanya pengembangan Bandar Udara Perintis Harun Thohir, Bawean.

Dalam pengembangannya bandar udara tersebut akan mengalami penambahan pengguna. Sehingga perlu diperhatikan terkait kenyamanan pengguna, baik termal, maupun akustik. Sasaran pengguna yang dimaksud adalah pegawai, penumpang, dan pengantar jemput. Karena tiap pengguna memiliki sensitifitas yang berbeda terkait termal. Seperti dalam penelitian [1] menyatakan bahwa rata-rata penumpang lebih dapat menyesuaikan kondisi dibandingkan pekerja yang lebih sensitif terhadap perbedaan suhu. Sedangkan terkait kenyamanan akustik juga penting, faktor yang menggangu adalah bising. Menurut Chaeran (2008) peningkatan tingkat kebisingan yang terus menerus dari berbagai aktifitas pada lingkungan Bandara dapat berujung kepada gangguan kebisingan, yaitu : 1. Efek psikologis pada manusia Kebisingan dapat membuat kaget, mengganggu dan mengacaukan konsentrasi, menginterferensi komunikasi dalam percakapan dan akan menginterferensi hasil pekerjaan dan keselamatan kerja. ; 2.
Efek fisis kebisingan dapat mengakibatkan penurunan kemampuan pendengaran dan rasa sakit pada tingkat yang sangat tinggi [2]

Selain itu, juga perlu diperhatikan terkait bentuk desain yang memperlihatkan arsitektur bawean. Agar mencerminkan bandara tersebut menjadi pintu gerbang yang mencirikan lokalitas arsitektur setempat.
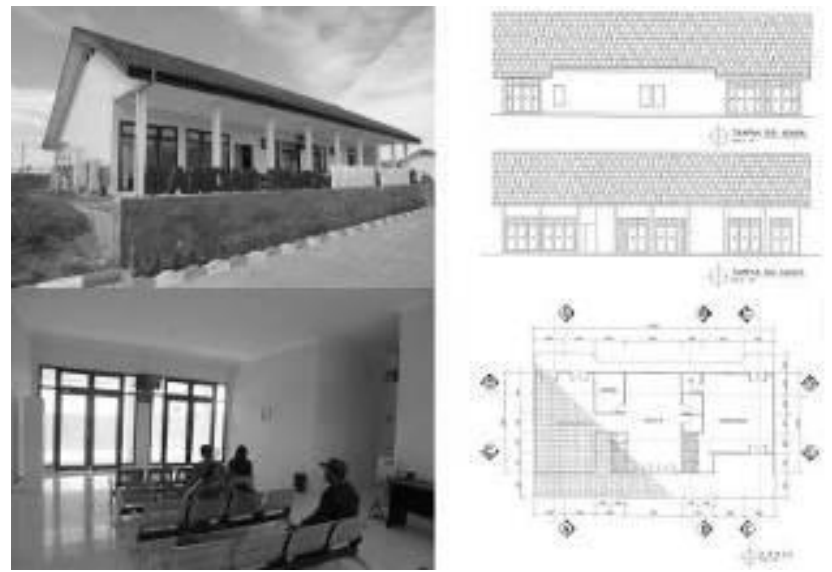

Gambar 1. Keadaan eksisting Bandar Udara Harun Thohir, Bawean.

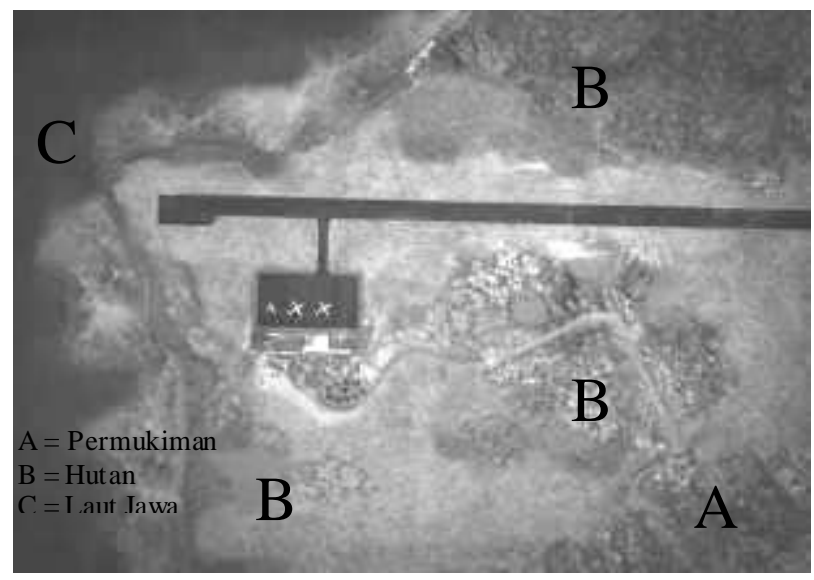

Gambar 2. Siteplan Obyek Rancang

\section{METODE PERACANGAN}

Dalam desain kali ini, pendekatan yang sesuai dengan isu adalah pendekatan secara tropis. Karena secara geografis letak tapak yang masih dalam lingkungan tropis. Selain itu arsitektur tropis erat kaitannya dengan kondisi termal dan juga lokalitas sekitaran tapak.

Poin utama dalam pertimbangan mendesain bangunan tropis adalah [2]: 
1. Meminimalisasi pertambahan panas salama siang hari

2. Memaksimalisasi pelepasan panas selama malam hari

3. Meminimalisasi pertambahan panas internal

4. Memilih site berdasarkan kriteria iklim mikro

5. Optimasi struktur bangunan

6. Mengontrol radiasi matahari

7. Memutar sirkulasi udara

\section{A. Metode}

Metode perancangan adalah transformasi, Transformasi dapat disepadankan dengan kata pemalihan, yang artinya perubahan dari benda asal menjadi benda jadiannya. Baik perubahan yang sudah tidak memiliki atau memperlihatkan kesamaan atau keserupaan dengan benda asalnya, maupun perubahan yang benda jadiannya masih menunjukan petunjuk benda asalnya [3]. Transformasi lumbung durung menjadi bentuk jadiannya, yaitu sebagai bangunan terminal Bandar Udara Harun Thohir melalui proses transformasi. [4] Proses transformasi ini merupakan bagaimana melakukan transformasi beberapa aspek, baik fisik, maupun non-fisik. Dalam tranformasi ini tidak hanyak ingin memindahkan aspek fisik saja. Tetapi juga apa yang terkait dalam aspek termal dan akustik. Jadi, segala konsiderasi yang dipilih dalam proses transformasi akan disesuaikan dengan aspek termal dan akustik.

\section{B. Aplikasi Metode}

\begin{tabular}{|c|c|c|}
\hline Elemen & Awal & Akhir \\
\hline \multirow{4}{*}{ Imej } & At ap memiliki sudut $60^{\circ}$ & Atap memiliki sudut $60^{\circ}$ \\
\hline & Material rumbia sebagai & Material sirap beton dan \\
\hline & $\begin{array}{l}\text { penutup atap (tidak } \\
\text { transparan) }\end{array}$ & $\begin{array}{l}\text { kaca sebagai penutup atap } \\
\text { (campuran) }\end{array}$ \\
\hline & Memiliki Jelapang & Memiliki jelapang \\
\hline \multirow{5}{*}{ Fungsi } & Menerima tamu & $\begin{array}{l}\text { Menerima orang pertama } \\
\text { kali sebelum masuk ke } \\
\text { Bawean }\end{array}$ \\
\hline & Aktivitas & Aktivitas berubah \\
\hline & Siang: menenun & \\
\hline & Malam: istirahat & \\
\hline & Lumbung Padi & Bandar udara \\
\hline \multirow{4}{*}{ Konstruksi } & Struktur panggung & Struktur panggung \\
\hline & Konstruksi kayu & $\begin{array}{l}\text { Campuran kayu laminasi, } \\
\text { beton, dan baja }\end{array}$ \\
\hline & Sambungan bertumpuk & $\begin{array}{l}\text { Sambungan ada yang } \\
\text { bertumpuk }\end{array}$ \\
\hline & Memiliki empat kolom & Jumlah kolom bertambah \\
\hline \multirow[t]{2}{*}{ Termal } & $\begin{array}{l}\text { Tidak memiliki dinding } \\
\text { pada level } \\
\text { (penghawaan silang) }\end{array}$ & $\begin{array}{l}\text { Memiliki konsep 'minim } \\
\text { dinding' }\end{array}$ \\
\hline & $\begin{array}{l}\text { Menggunakan } \\
\text { pembayangan akibat atap }\end{array}$ & $\begin{array}{l}\text { Menggunakan } \\
\text { pembayangan akibat atap }\end{array}$ \\
\hline Akustik & $\begin{array}{l}\text { Merasa nyaman } \\
\text { walaupun tidak memiliki } \\
\text { dinding }\end{array}$ & Bising dapat dinikmati \\
\hline
\end{tabular}

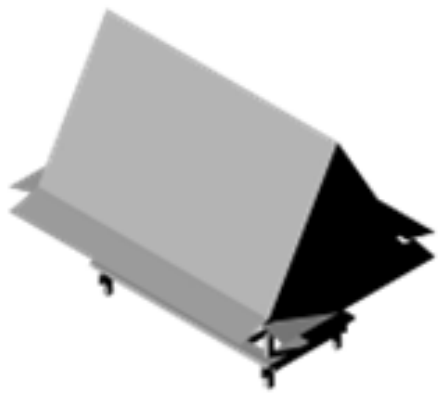

Gambar 3. Lumbung dhurung.

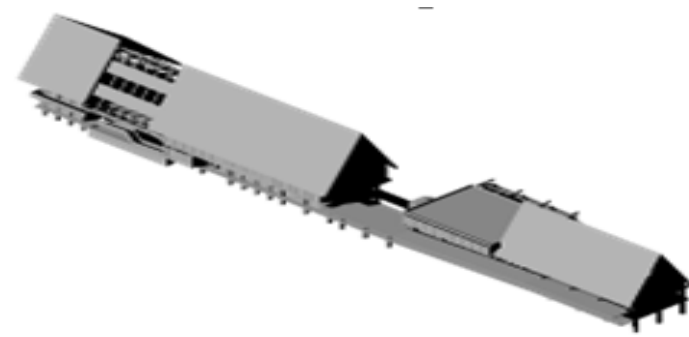

Gambar 4. Bentuk Jadian Bandar Udara.

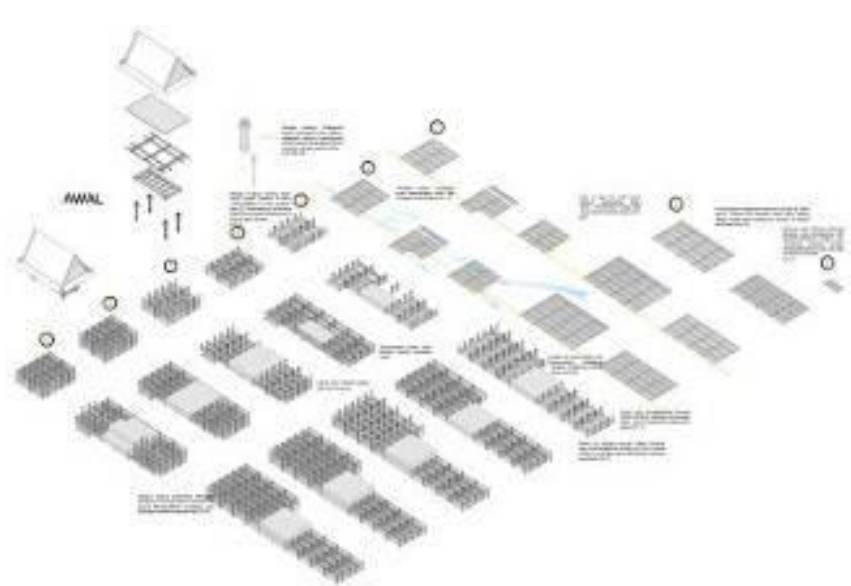

Gambar 5. Transformasi Bentuk Bangunan

\section{Konsep Desain}

\section{- Konsep Ruang Dalam}

Konsep ruang dalam disesuaikan dengan kebutuhan penggunanya. Secara garis besar kebutuhan berasal dari standar yang sudah ditetapkan [3]. Untuk desain terkait kenyamanan termal dan akustik akan disesuaikan berdasarkan pengguna, kegiatan, dan waktu pemakaian.

Tabel 1.

Konsep Ruang Dalam terkait Termal

\begin{tabular}{|c|c|c|c|c|}
\hline Nama & Pengguna & Kegiatan & Durasi & $\overline{\mathrm{A} / \mathrm{P}}$ \\
\hline Area check-in & Penumpang & Lapor diri & $\begin{array}{l}15 \\
\text { menit }\end{array}$ & $\mathrm{P}$ \\
\hline Ruang tunggu & Penumpang & $\begin{array}{l}\text { Menunggu } \\
\text { keberangkatan }\end{array}$ & $\begin{array}{l}1-2 \\
\text { jam }\end{array}$ & A \\
\hline Kantor Pegawai & $\begin{array}{l}\text { Pegawai } \\
\text { UPBU }\end{array}$ & Bekerja & $8 \mathrm{jam}$ & A \\
\hline $\begin{array}{l}\text { Kantor } \\
\text { Maskapai }\end{array}$ & $\begin{array}{l}\text { Pegawai } \\
\text { maskapai }\end{array}$ & Bekerja & 8 jam & A \\
\hline
\end{tabular}

Tabel 2.

Konsep Ruang Dalam terkait Termal

\begin{tabular}{|c|c|c|c|c|}
\hline Nama & Pengguna & Kegiatan & Durasi & $\overline{\mathrm{B} / \mathrm{T}}$ \\
\hline Area check-in & Penumpang & Lapor diri & $\begin{array}{l}15 \\
\text { menit }\end{array}$ & $\overline{\mathrm{B}}$ \\
\hline Ruang tunggu & Penumpang & $\begin{array}{l}\text { Menunggu } \\
\text { keberangkatan }\end{array}$ & $\begin{array}{l}1-2 \\
\text { jam }\end{array}$ & $\mathrm{T}$ \\
\hline Kantor Pegawai & $\begin{array}{l}\text { Pegawai } \\
\text { UPBU }\end{array}$ & Bekerja & 8 jam & $\mathrm{T}$ \\
\hline $\begin{array}{l}\text { Kantor } \\
\text { Maskapai }\end{array}$ & $\begin{array}{l}\text { Pegawai } \\
\text { maskapai }\end{array}$ & Bekerja & 8 jam & $\mathrm{T}$ \\
\hline
\end{tabular}

Lalu, desain terkait menyajikan kesan lumbung dhurung 
diciptakan melalui bagaimana pengguna berinteraksi langsung dengan detail bangunan yang mirip dhurung.

- $\quad$ Konsep Fasad dan Bentuk

Konsep bentuk dan fasad menggunakan bentuk yang menggambarkan identitas tempat. Diharapkan dengan adanya proses transformasi lumbung dhurung menjadi bandar udara ini dapat menyampaikan kesan adanya bandar udara ini sebagai penyambut paling pertama sebelum menuju bawean. Dengan adanya transformasi bentuk lumbung dhurung juga memungkinkan untuk terintegrasi dengan aspek termal dan akustik. Contohnya, atap dengan sudut $60^{\circ}$ dan memiliki rongga memiliki performa terbaik. Seperti atap kampung srotongan, menurut Samodra [4] atap tersebut memiliki performa terbaik akibat sudut, luasan, dan rongga di atap.

- Konsep Zoning / Tatanan Massa

Konsep zonifikasi untuk obyek rancang ini disesuaikan dengan aspek teknis standar bandara [5], arah angin dan juga jarak dengan fasilitas sisi udara. Agar angin dapat dimanfaatkan sebagai pendinginan pasif dan juga bising dapat diminimalisasi.

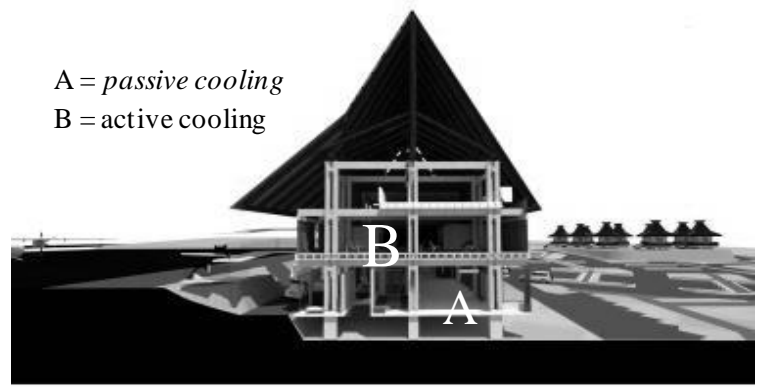

Gambar 6. Konsep penghawaan ruang dalam.

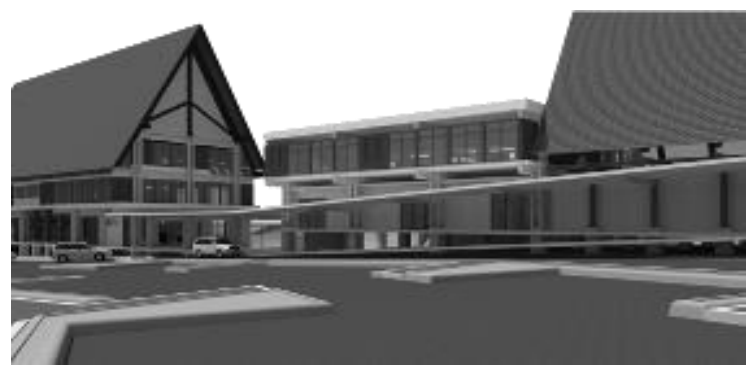

Gambar 7 . Hasil transformasi lumbung dhurung.

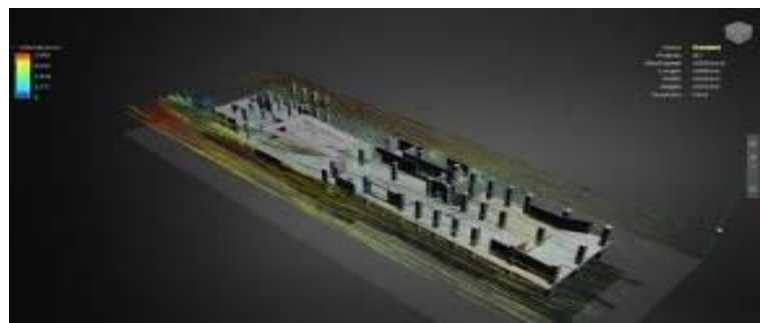

Gambar 8. Hasil simulasi angin.

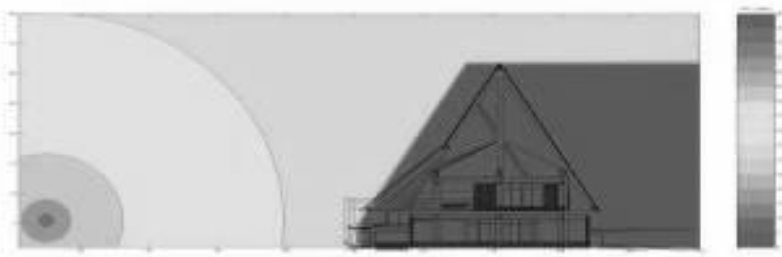

Gambar 9. Hasil simulasi transmision lost kibat pertambahan jarak dan perubahan maerial.

\section{HASIL RANCANGAN}

\section{A. Ruang Dalam}

Seperti yang sudah dijelaskan sebelumnya, dari standar yang sudah ada akan diberikan keperluar khusus, hal tersebut terkait pengguna, kegiatan, dan waktu.

Dapat terlihat dari beberapa ruangan, seperti area checkin, sesuai dengan Tabel 1 yang diutamakan adalah penumpang yang melakukan lapor diri tidak lebih dari 15 menit. Sehingga memungkinkan area tersebut cukup menggunakan pendinginan pasif. Tetapi, akibat adanya pendinginan pasif menyebabkan konskuensi bising yang masuk. Bukaan pada dinding tropis memang berpengaruh terhadap pendinginan pasif, lalu di sisi lain juga akan memasukkan bising yang searah dengan vektor angin [5]. Tetapi itu bukan menjadi masalah. Karena orang cenderung tidak lama berada di sana. Terlebih lagi juga kesesuaian akan lumbhung dhurung yang tidak memiliki dinding. Sehingga muncul konsep minim dinding.

Lalu, ruang tunggu, biasanya penumpang berada di sana 1-2 jam. Hal tersebut lebih lama dibandingkan waktu lapor diri yang singkat. Sehingga perlu adanya pendinginan aktif dalam ruangan. Hal tersebut juga menyebabkan dinding menjadi cenderung tertutup. Sehingga akan meminimalisasi kebisingan. Karena lumbung dhurung memiliki fungsi penyimpanan di level atas akibat adanya kontrol udara. Akhirnya, posisi penempatan ruang tunggu berada di lantai dua.

Lalu, ruangan yang terkait operasional bandar udara, pegawai yang ada cenderung menghabiskan waktu yang panjang setiap harinya. Sehingga pegawai cenderung lebih sensitif terhadap kualitas kenyamanan suhu. Untuk itu, ruang-ruang tersebut menggunakan pengdinginan aktif dan juga tertutup. Hal tersebut berkaitan erat dengan efektifitas bekerja.

\section{B. Fasad dan Bentuk}

Fasad bangunan terbentuk dari proses tranformasi lumbung dhurung yang disesuaikan dengan aspek termal dan akustik. Dari proses transformasi ini diharapkan tidak hanya menampilkan bentuk. Secara keseluruhan bangunan ini memiliki kemiripan, yaitu : 1. Memiliki bentuk atap yang sama namun material berbeda ; 2. Bangunan berbentuk panggung ; 3. Level 1 memiliki konsep minim dinding ; 4. level 2 tertutup; 5. Material kolom dari kayu glulam; 6 .

Diharapkan dengan adanya bentuk yang memiliki kemiripan dengan lumbung dhurung menggambarkan fungsi yang sama, sebagai penyambut paling pertama sebelum masuk ke area dalam.

\section{Tatanan Massa}

Zonifikasi didasarkan oleh standar dan juga kebutuhan teknis. Seperti bangunan terminal dan juga kantor operasional bandara terletak di dekat apron. Akibatnya ada konsekuensi bising yang didapatkan. Tetapi dapat diminimalisasi dengan pemberian jarak, perbedaan level dan juga pemilihan material. Untuk orientasi, dari bangunan tidak menghalangi angin dan dapat memasukkan angin ke dalam bangunan. Sedangkan bangunan penginapan terletak jauh dari apron. Sehingga dengan adanya jarak yang jauh dan juga barrier berupa bangunan lain menyebabkan bising lebih dapat terminimalisasi. Untuk penataan penginapan diharapkan dapat melalui sela-sela bangunan. 


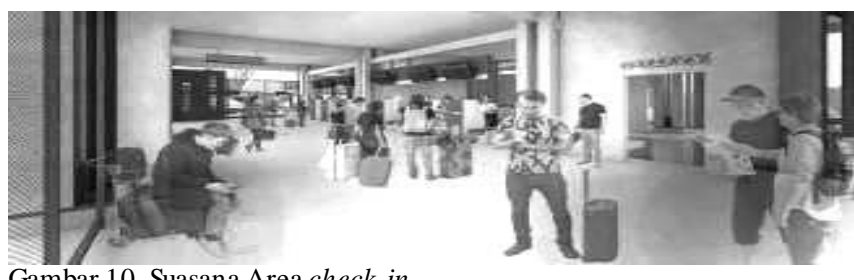

Gambar 10. Suasana Area check-in.

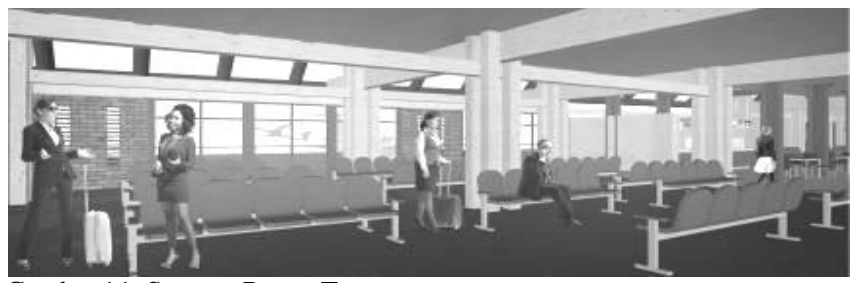

Gambar 11. Suasana Ruang T unggu.

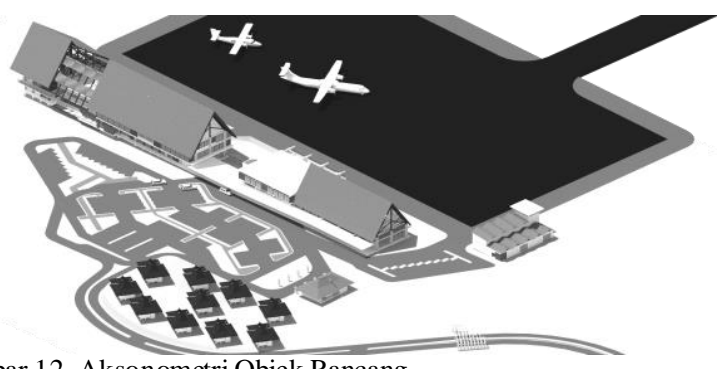

Gambar 12. Aksonometri Objek Rancang

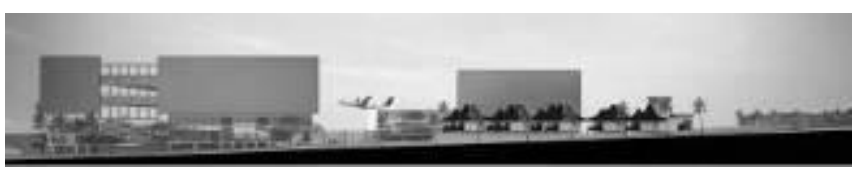

Gambar 13 Tampak Utara

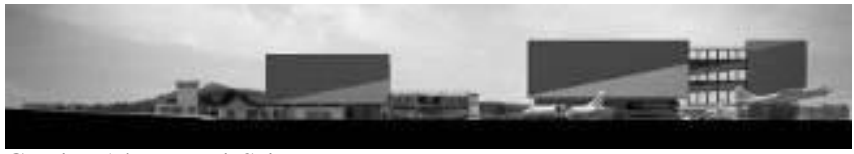

Gambar 14 T ampak Selatan

\section{KESIMPULAN}

Pengembangan bandar udara ini diharapkan dapat memenuhi kebutuhan kegiatan penerbangan. Juga, diharapkan kenyamanan termal dan juga akustik tetap terjaga kualitasnya agar pengguna semakin merasa nyaman. Tidak hanya hanya, tapi munculnya integrasi antara aspek termal dan akustik. Selain itu, diharapkan bandar udara ini sebagai pintu gerbang yang mewakilkan lumbung dhurung pada tiap rumah di Bawean, dengan memunculkan kesan pada bentukbangunan dan detail yang ada.

\section{UCAPAN TERIMA KASIH}

Penulis mengucapkan terima kasih kepada Jurusan Arsitektur, Direktorat Jendral Pendidikan Tinggi selaku

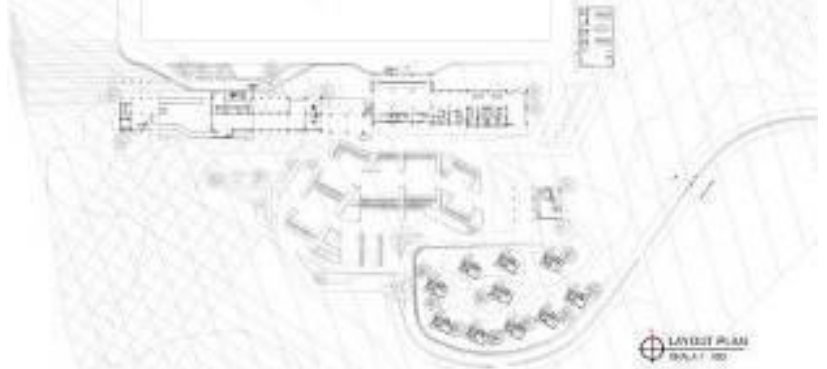

Gambar 15. Layout Objek Rancang.

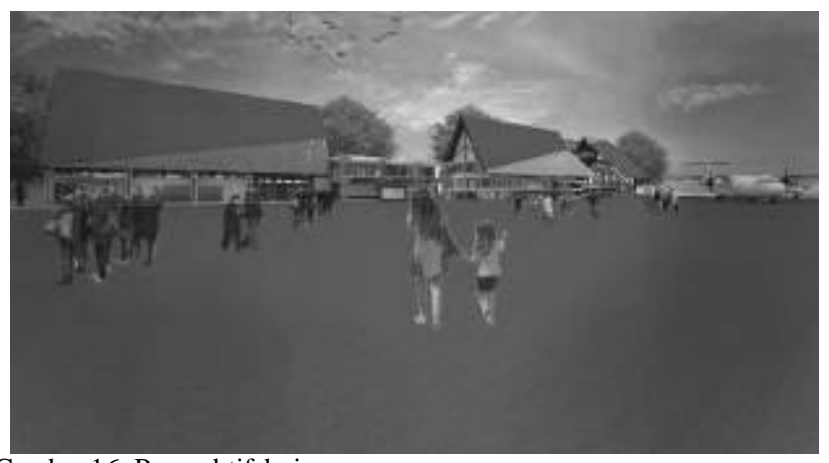

Gambar 16. Perspektif dari apron.
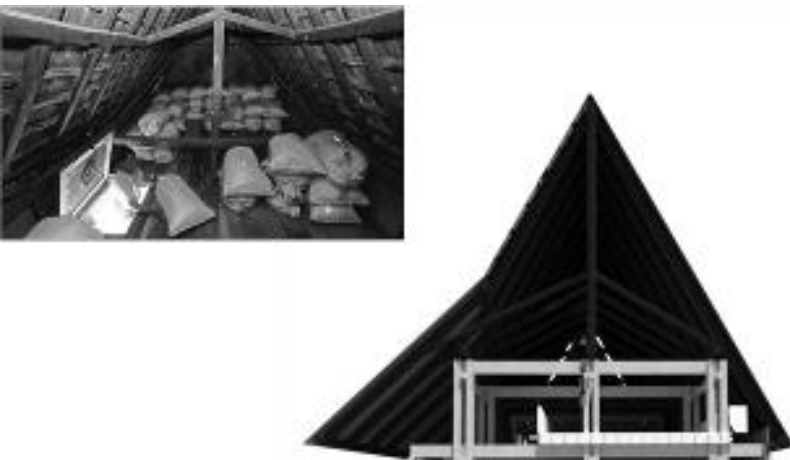

Gambar 17. Struktur atap lumbung dan bandar udara terdesain.

pemberi beasiswa. Terima kasih kepada keluarga yang selalu mendukung dan mendoakan, serta kepada seluruh pihak yang telah membantu dan mendukung dalam penyelesaian jurnal ini.

\section{DAFTAR PUSTAKA}

[1] A. Kotopouleas and M. Nikolopoulou, "Thermal comfort conditions in airport terminals: Indoor or tran sition spaces?," 2016.

[2] P. Gut and D. Ackerknecht, "Climate Responsive Building," SKAT-Swiss Cent. Dev. Coop. Technol. Manag., pp. 161-170, 1993.

[3] J. Prijotomo, Pasang Surut Arsitekturdi Indone sia. Sur abay a: CV. Ardjun, 1988.

[4] F. Samodra, "Analysis of solar geometry influences to the roof of the roof architecture in tropical regian," 2019.

[5] F. Samodra, "Site barrier optimization on in te grating thermal Comfort with noise propagation control," 2017. 